\title{
SYNCHRONIZATION PROTOCOLS IN SPANISH MERINO SHEEP: REDUCTION IN TIME TO ESTRUS BY THE ADDITION OF ECG TO A PROGESTERONE-BASED ESTRUS SYNCHRONIZATION PROTOCOL
}

\author{
Juan Carlos Gardón ${ }^{1}$, Begoña Escribano², Susana Astiz ${ }^{3}$, Salvador Ruiz ${ }^{4 *}$ \\ 'Department of Applied Science and Technology, Catholic University of Valencia "San Vicente Mártir" \\ 46001 Valencia, Spain \\ ${ }^{2}$ Department of Cell Biology, Immunology and Physiology, Cordoba University, \\ 14071 Córdoba, Spain \\ ${ }^{3}$ Department of Animal Reproduction, INIA, 28040 Madrid, Spain \\ ${ }^{4}$ Department of Physiology, Murcia University, 30100 Murcia, Spain \\ •Corresponding author: sruiz@um.es
}

\begin{abstract}
An appropriate management of reproduction allows ewes to breed at a more intensive rhythm, more compatible with economic efficiency of farms. Hence, the objectives of the present work were to evaluate a traditional estrus synchronization protocol (based on medroxyprogesterone acetate-impregnated intravaginal sponges combined or not with equine chorionic gonadotropin) on a Merino sheep herd during the breeding season, in order to determine the best working protocol for this breed. A total of 277 sheep, blocked by age (200 ewes and 77 ewe lambs) were randomly allocated to four groups, two of ewes $(\mathrm{E}$ and $\mathrm{Ee})$ and two of ewe lambs ( $\mathrm{L}$ and $\mathrm{Le})$. All females received $60 \mathrm{mg}$ MAP (medroxyprogesterone acetate) sponges on the first day. At the day of removal the animals of groups Ee and Le received 450 IU of eCG (equine chorionic gonadotropin). Mean estrus synchronization rate was $\mathbf{9 2 . 0 6 \%}$ and similar among groups. Time to estrus was shorter for Ee $(46.93 \pm 12.44 \mathrm{~h})$ and Le $(44.34 \pm 10.76 \mathrm{~h})$, when compared to treatments without eCG (60.60 $\pm 20.46 \mathrm{~h}$ and $58.68 \pm 17.72 \mathrm{~h}$ for $\mathrm{E}$ and $\mathrm{L}$, respectively; $\mathrm{P}<0.05$ for both). Pregnancy rates were 71.35 and $72.86 \%$ for ewes and ewe lambs, respectively, and similar among groups. Lambing rates were lower in ewes (1.36) than in ewe lambs (1.85) with no significant effect of eCG. The study demonstrates the efficacy of the synchronization method with MAP and the reduction in the time to estrus induced by eCG in Spanish Merino ewes and ewe lambs during the breeding season.
\end{abstract}

Key words: Spanish Merino sheep, age, estrus synchronization, reproductive response, eCG

In the last decades different reproductive control methods have been developed, allowing significant progress improving the production of commercial herds. From the research conducted by Robinson (1965), different synthetic progesterone ana- 
logues are used in the regulation of the estrous cycle in small ruminants during or outside of the breeding season (Titi et al., 2010; Awel et al., 2009; Martemucci and D'Alessandro, 2011; Abecia et al., 2012). The most used protocol is based on intravaginal sponges impregnated with medroxyprogesterone acetate (MAP) and fluoroprogesterone acetate (FGA) during 12 or 14 days, followed by the administration of equine chorionic gonadotropin (eCG) at device withdrawal (Wildeus, 2000; Boscos et al., 2002; Quintero-Elisea et al., 2011).

In numerous studies in small ruminants a high degree of estrus synchronization has been reported $(>80 \%)$ with the use of $60 \mathrm{mg}$-MAP impregnated sponges (Wildeus, 2000; Simonetti et al., 2002; Dogan and Nur, 2006). Indeed, the distribution of the time to estrus obtained varies depending on whether eCG is included or not and on animal category (Das et al., 2000; Viñoles et al., 2001; Dogan and Nur, 2006). When fertility from natural estrus is compared to that induced by progestagens, reports show lower results which are attributed to different causes, such as alterations in ovulation quality, hormonal release patterns and sperm transport (Simonetti et al., 2000; Ungerfeld and Rubianes, 2002; Zeleke et al., 2005). Nevertheless, in fixedtime artificial insemination systems, estrus and ovulations outside normal ranges (50-60 h) are not usually accounted for and, as a consequence, a certain percentage of females are actually not fertilized (Cline et al., 2001; Dogan and Nur, 2006; Olivera-Muzante et al., 2011).

The use of eCG aims to improve estrus synchronization, follicular maturation, ovulation rate and fertility, with doses ranging from 300 to $600 \mathrm{IU}$, according to breed, animal weight and time of the year (Boscos et al., 2002; Dogan and Nur, 2006; Olivera-Muzante et al., 2011). Additionally, a superovulatory effect has been described on the induced estrus and the consequent prolificacy increment (Zeleke et al., 2005; Azawi et al., 2010; Quintero-Elisea et al., 2011). The efficacy of treatments depends on extrinsic and intrinsic factors. Extrinsic factors include the active principle of the drug, time of the year in which treatment is applied, the dose applied, duration and protocol design (Moeini et al., 2007; Knights et al., 2011; McCappin and Murray, 2011). Intrinsic factors include breed and age. All of these factors, whether isolated or as a group, define the ovarian status at the moment of applying the synchronization protocols and, as a consequence, the responses (Viñoles et al., 2005; Kareta et al., 2006; Scaramuzzi et al., 2006).

Merinos are the most internationally known Iberian sheep. The Merino sheep originated in the Iberian Peninsula and shows a mixed aptitude, which currently produces the milk used to prepare high quality cheese ("Torta del Casar", "Queso de la Serena" and "Queso de los Pedroches") whose production is strictly regulated by legislation protecting Designation of Origin. Merinos on the other hand are characterized by their fine wool (Pedrosa et al., 2007) and by their high quality meat lambs named "Cordero de Extremadura, CORDEREX" (Cambero, 1999; Juárez et al., 2007). The differences in reproductive issues among sheep breeds are well known (Ranilla et al., 1994). The different responses to the different reproductive hormones used normally for synchronization have been described (Abecia et al., 2011, 2012). Likewise, it is well known that there is a clear link between reproductive and productive performance in all animal production species (El-Saied et al., 2006). Hence, 
for producers exploiting this old and highly genetically valuable ovine breed it is important to optimize efficiency in order to guarantee sustainability of their farms.

Therefore, the objective of the present study was to determine estrus occurrence and distribution after a traditional estrus synchronization protocol (MAP intravaginal sponge with or without eCG) in a herd of Spanish Merino, controlling the age of the ewes, in order to determine the best synchronization methods specifically for this breed.

\section{Material and methods}

\section{Experimental animals}

A total of 200 ewes, 2.5 to 5.5 years old, weighing between 45 and $55 \pm 9.70 \mathrm{~kg}$, body condition scores (BCS) between 3.0 and 3.5 on a 1-5 scale (Russel, 1991) and 77 ewe lambs, 12 to 15 months old, 40-45 $\pm 8.92 \mathrm{~kg}$ with a similar BCS, sexually mature and clinically healthy of the Spanish Merino breed, were used. In this study animals were housed in one flock in the facilities of a private farm located in Écija (latitude $5^{\circ} 04^{\prime} 45^{\prime \prime} \mathrm{O}$, longitude $37^{\circ} 32^{\prime} 28^{\prime \prime} \mathrm{N}$ ) in Seville, Spain, during November which implied a median length of 10.06 hours a day, with a decreasing rate of the photoperiod of $1.73 \mathrm{~min} /$ day until the $21 \mathrm{st}$ of December. The animals were managed under the same conditions. They were fed with $600 \mathrm{~g} / \mathrm{head} /$ day pelleted concentrate mixture with $14 \%$ crude protein (corn, wheat bran and unhulled cotton seed) and clover hay and wheat straw were provided. Water and a mineral salt lick were provided ad libitum. The management of the animals did not change throughout the entire experimental period.

The experiment was carried out according to the Spanish Policy for Animal Protection RD1201/05, which meets the European Union Directive 86/609 about the protection of animals used in experimentation. To visualize the reproductive health status in the ewes and the sexual maturity in ewe lambs, females were scanned by transrectal ultrasonography with an $8 \mathrm{MHz}$ linear probe (Aquila, Esaote-Pie Medical, Maastricht, The Netherlands). Ewe lambs with ovaries with corpora lutea were considered sexually mature. Twenty-eight Merino rams, sexually mature with proven fertility, clinically healthy, ages between 2.5 and 4.0 years old, and weighing between 55 and $65 \mathrm{~kg}$ were used.

\section{Estrus synchronization}

Ewes and ewe lambs were treated with $60 \mathrm{mg}$-MAP intravaginal sponges (Sincrogest ${ }^{\circledR}$, Ovejero Lab, Leon, Spain). Prior to insertion, sponges were impregnated with antibiotics (framicetin sulphate $40 \mathrm{mg}$ and sulathiazol $960 \mathrm{mg}$, Ovejero Lab, Leon, Spain) and inserted in the vagina after thorough cleaning of the vulvar perineum. Sponges were placed into the vaginal canal as far as possible by means of an applicator previously disinfected with a $5 \%$ solution of polvidine (betadine, Meda Pharma SA, Spain). Sponges remained in the females until day 12 at which time an injection of $450 \mathrm{IU}$ of eCG (Serigan ${ }^{\circledR}$, Ovejero Lab, Leon, Spain) was administered i.m. (Groups Ee and Le) or not (Groups E and L). 
Females were allocated randomly to one of four treatment groups without previous administration of any other hormonal product after the last lambing:

Group E $(n=100)$ : ewes received a MAP sponge.

Group Ee $(n=100)$ : ewes received a MAP sponge $+450 \mathrm{IU}$ of eCG, i.m.

Group L ( $\mathrm{n}=39)$ : ewe lambs received a MAP sponge.

Group Le ( $\mathrm{n}=38)$ : ewe lambs received a MAP sponge $+450 \mathrm{IU}$ of eCG, i.m.

The synchronization of the animals was performed in two phases. The first phase included the half of each group (Group E n=50; Ee n=50; L n=20 and Le n=18) and the rest of the ewes and lambs were synchronized during the second phase. The interval between the two phases was 15 days. Females of $\mathrm{E}$ and $\mathrm{L}$ groups received placebo intramuscular injection of saline solution.

\section{Estrus detection and mating}

The rams were randomly assigned to the groups. After sponge withdrawal females were placed with rams for four days, at a 5:1 female:male ratio. Rams were painted with special colored pencils at the preputial region and on the brisket. Thrice daily (morning, afternoon and night), at regular intervals, mounting and standing behavior was observed and marked females were separated from the flock. Percentage of females with detected estrus (ER) was calculated in the following intervals to evaluate time to estrus (TE): 24-31, 32-39, 40-47, 48-55, 56-61, 62-69, 70-77, 78-85, 86-93 and 94-102 hours after sponge withdrawal.

\section{Pregnancy detection}

Thirty days after males were withdrawn, pregnancy was confirmed by transrectal ultrasonography with an $8 \mathrm{MHz}$ linear probe (Aquila, Esaote-Pie Medical, Maastricht, The Netherlands). Pregnancy rate (PR) was calculated as total pregnant per synchronized sheep. Lambing rate (LR), calculated as total lambs per lambing, was recorded for all animals.

\section{Statistical analysis}

The effects of treatment on the $2 \times 2$ factorial scheme were studied in the case of continuous variables (TE and LR) by one-way analysis of variance (ANOVA) followed by Duncan test used to identify different groups. Concrete variables (ER and PR) were compared with a Chi square test. Significant differences were considered at $\mathrm{P}<0.05$.

\section{Results}

Reproductive parameters (TE, ER, PR and LR) observed in the different experimental groups are shown in Figure 1. There were no significant differences among groups neither in the case of ER nor in the PR of animals, with the average estrous rate following MAP sponge being $92.06 \%$. PR was 71.35 and $72.86 \%$ for ewes and ewe lambs, respectively, and similar among groups. Average time to estrus was sig- 
nificantly reduced with the addition of eCG $(60.60 \pm 20.46 \mathrm{~h}$ vs. $46.93 \pm 12.44 \mathrm{~h}$ for $\mathrm{E}$ and Ee and $58.68 \pm 17.72 \mathrm{~h}$ vs. $44.34 \pm 10.76 \mathrm{~h}$ for L and Le, respectively; $\mathrm{P}<0.05$ for both). No effect of eCG was found in the lambing rate, but age significantly affected the LR, with lambs lambing more lambs/lambing (1.36 vs. 1.85 for E and L, respectively; $\mathrm{P}<0.05)$.
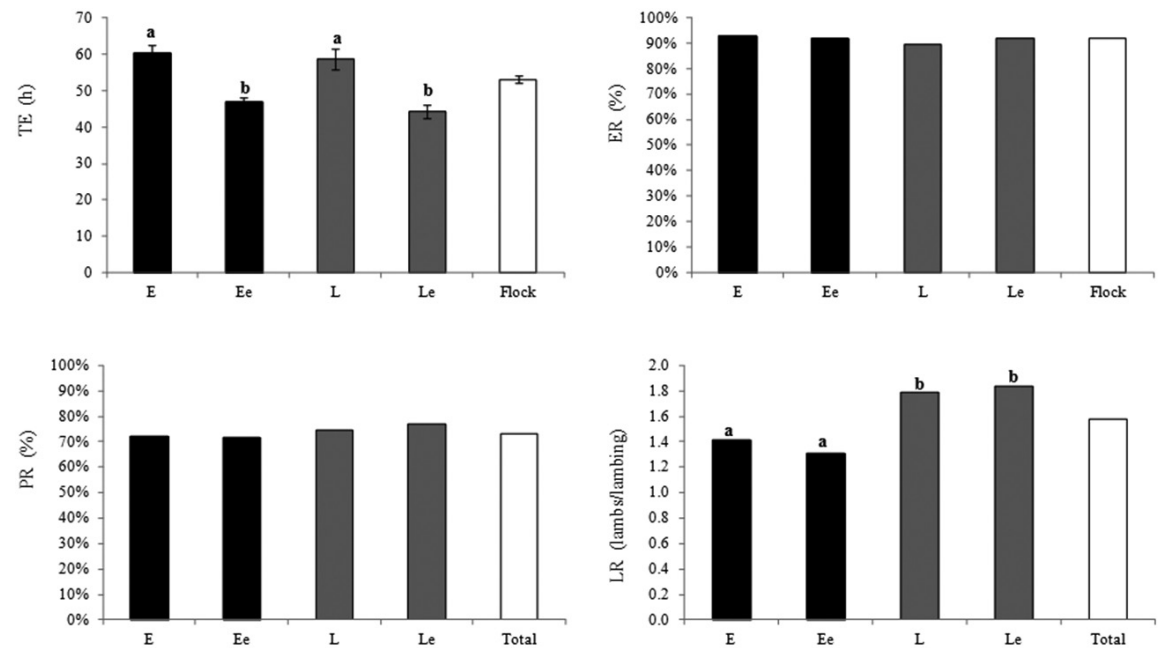

Figure 1. Time to estrus (TE, hours after MAP withdrawal), estrus rate (ER, \%), pregnancy rate (PR, $\%$ ) and litter size (LS, lambs/lambing) of Spanish Merino ewes (E) and ewe lambs (L) synchronized with $60 \mathrm{mg}$ medroxyprogesterone acetate sponges for 12 days and treated with (groups Ee and Le) or without (groups $\mathrm{E}$ and $\mathrm{L}$ ) eCG at sponge removal. Bars with different letters differ $(\mathrm{P}<0.05)$

Table 1. Estrus distribution in ewes and ewe lambs treated with 60 mg MAP impregnated sponges with or without $450 \mathrm{IU}$ of eCG

\begin{tabular}{l|cc|c|c}
\hline \multirow{2}{*}{$\begin{array}{c}\text { Estrus detection } \\
\text { intervals } \\
\text { (hours) }\end{array}$} & \multicolumn{4}{|c}{ Estrus distribution (\%) } \\
\cline { 2 - 5 } & $\begin{array}{c}\text { Group E } \\
(\mathrm{n}=100)\end{array}$ & $\begin{array}{c}\text { Group Ee } \\
(\mathrm{n}=100)\end{array}$ & $\begin{array}{c}\text { Group L } \\
(\mathrm{n}=39)\end{array}$ & $\begin{array}{c}\text { Group Le } \\
(\mathrm{n}=38)\end{array}$ \\
\cline { 2 - 5 } & 5.38 & $9.78^{*}$ & 5.71 & $11.43^{*}$ \\
$24-31$ & 17.20 & 15.22 & 11.43 & $22.86^{*}$ \\
$32-39$ & 7.53 & $23.91^{*}$ & 8.57 & $31.43^{*}$ \\
$40-47$ & 10.75 & $25.00^{*}$ & 14.29 & 17.14 \\
$48-55$ & $11.83^{* *}$ & 15.22 & $20.00^{* *}$ & $11.43^{*}$ \\
$56-61$ & 13.98 & $6.52^{*}$ & 17.14 & 5.71 \\
$62-69$ & 12.90 & $4.35^{* *}$ & 8.57 & $0.00^{* *}$ \\
$70-77$ & 5.38 & $0.00^{*}$ & 5.71 & $0.00^{*}$ \\
$78-85$ & 8.60 & $0.00^{*}$ & 5.71 & $0.00^{*}$ \\
$86-93$ & 6.45 & $0.00^{*}$ & 2.86 & $0.00^{*}$ \\
$94-102$ & & & & 3 \\
& 7 & 8 & 4 & 3 \\
N/R (n) & & & & \\
\hline
\end{tabular}

Values with distinct superscripts differ: * within female age category (ewes vs. ewe lambs) and ** within experimental groups [with eCG $(\mathrm{Ee}$ and $\mathrm{Le})$ vs. without eCG $(\mathrm{E}$ and $\mathrm{L})](\mathrm{P}<0.05)$.

$\mathrm{N} / \mathrm{R}$ : number of females that showed no signs of heat. 
Interval of time on estrus distribution is recorded in Table 1. There was a significant difference $(\mathrm{P}<0.05)$ between the groups that received eCG $(\mathrm{Ee}$, and Le) and those that did not receive the hormone ( $\mathrm{E}$ and $\mathrm{L}$ ), indicating a reduction in the time to onset of estrus induced by eCG effect.

\section{Discussion}

Optimizing management procedures to improve the productive and reproductive potential of Spanish Merino sheep may be extremely important for producers. The present study offers information on the specific reproductive behavior of Spanish Merino sheep after estrus synchronization with MAP sponges and eCG or not. The results of this study indicate that Merino sheep can be successfully synchronized with these protocols, and that the addition of eCG to the protocol shortens the time to estrus, without a reduction in pregnancy or lambing rate.

The use of MAP intravaginal sponges has been demonstrated as an efficient method of estrus synchronization during the ovine reproductive season. In this work, the percentage of estrus synchronization in the general herd was $92.06 \%$. Such a high degree of synchronization has been achieved by other investigators in other breeds (Wildeus, 2000; Barrett et al., 2004; Olivera-Muzante et al., 2011).

After the protocols with eCG (Groups Ee and Le), the percentage of synchronization was similar between ewe lambs and ewes, which corroborates the results from other studies (Moses et al., 1997; Stellflug et al., 2001) where similar estrus rates were observed. However, the findings of the current study do not support previous research of Alberio et al. (1994) that reported lower estrus rates in ewe lambs compared to ewes. A possible explanation for these differences may be attributed to the different breeds, nutrition, time of the year, utilization and type of gonadotropin used by the different authors (Zeleke et al., 2005; Kareta et al., 2006; McCappin and Murray, 2011); such factors have been described as having possible impacts on estrus detection (Scaramuzzi et al., 2006; Knights et al., 2011; Quintero-Elisea et al., 2011). In fact, estrus rates of eCG-treated females in this study are similar to those previously reported (Simonetti et al., 2000; Dogan and Nur, 2006).

Time to estrus in group Ee ranged between 24-31 and 70-77 h after MAP removal, whilst in lambs with eCG (Le) TE ranged between 24-31 and 62-69 h. Differences in estrus distribution between ewe lambs and ewes due to eCG utilization have been described previously (Simonetti et al., 1999, 2000). Although the current results differ from some published studies (Quirke et al., 1981; Ainsworth and Wolynetz, 1982) with shorter TE intervals in ewes than in lambs, they are consistent with those of Moses et al. (1997). In the groups without eCG (E and L), the time to estrus ranged between 24-31 h and 94-102 h. These findings are in agreement with those reported in other sheep breeds and experimental conditions (Simonetti et al., 2000; Viñoles et al., 2001; Dogan and Nur, 2006) in which a positive effect of eCG in both ewes and lambs is reported. A reduction of time to estrus as well as a higher concentration of 
sheep showing estrus are an advantage in the reproductive management of flocks. The knowledge of these facts is important when artificial synchronization or short synchronization protocols should be implemented. These results corroborate those reported by Cline et al. (2001), Zeleke et al. (2005) or Dogan and Nur (2006).

The use of eCG has been somewhat controversial in terms of fertility. In the present study no reductions in fertility nor prolificacy were associated with eCG administration. Although these results differ from some published studies (Zeleke et al., 2005; McCappin and Murray, 2011) which reported higher fertility rates in sheep from other breeds or even a reduction when eCG was added, they are consistent with those of Simonetti et al. (2000), Ungerfeld and Rubianes (2002) or Quintero-Elisea et al. (2011).

Another important application of eCG in ovine is to increase prolificacy rates by modifying the ovulatory rate which depends on the dosage used (Boscos et al., 2002). Nevertheless, there is a great variability in responses that may be associated with breed, individuals within a breed, female category, time of the year and general animal condition (Samartzi et al., 1995; Boscos et al., 2002). Prolificacy in the eCG treated Merino sheep (Ee and Le) was similar to that reported by Simonetti et al. (2002) but lower than that described by Maxwell (1986).

Different studies clearly showed that an i.m. eCG injection at a dose recommended for estrus synchronization induced anti-eCG antibody production, which in turn produced negative effects when the next treatment was applied (Bodin et al., 1997). Animals in this study were not treated with eCG previously during the preceding years. So, no negative effects were attributed to this fact in the estrous synchronization program utilized.

Finally, age significantly affected prolificacy with higher rates in ewe lamb vs. ewes, independent of the use of eCG. Similar results were reported in different breeds (Anel et al., 2005; Zeleke et al., 2005; Fukui et al., 2010). This could be understandable based on the fact that compared with young ewes, aged ewes have increased risks of reproductive disorders and decreased rates of ovulation with quality ovulated oocytes causing this difference, which could be the case in the present study.

In conclusion, estrus of Spanish Merino ewes and ewe lambs was successfully synchronized with traditional MAP sponge protocols and the addition of eCG on the day of MAP withdrawal which resulted in a reduction of the time to estrus interval. These results will help farmers to improve the reproductive management of this Spanish sheep breed.

\section{References}

A b e c i a J.A., F or c a d a F., G on zález-B u lnes A. (2011). Pharmaceutical control of reproduction in sheep and goats. Vet. Clin. N. Am-Food A., 27: 67-79.

A b e c i a J.A., F or c a d a F., G on zález-B u ln e s A. (2012). Hormonal control of reproduction in small ruminants. Anim. Reprod. Sci., 130: 173-179. 
A insw orth L., Woly netz M.S. (1982). Synchronization of estrus and reproductive performance of ewes treated with synthetic progestogens administered by subcutaneous ear implant or by intravaginal sponge pessary. J. Anim. Sci., 54: 1120-1127.

A l b e ri o R., Sá n c he z H.E., Ví v o li C. (1994). Validación de los resultados de inducción y sincronización de celos en ovinos por medio de progestágenos. Ensayos a campo. Rev. Argent. Prod. Anim., 14: 115-116.

Anel L., Ka abi M., Abroug B., Alvarez M., Anel E., B o ixo J.C., D e La Fuente L.F., D e P a z P. (2005). Factors influencing the success of vaginal and laparoscopic artificial insemination in Churra ewes: a field assay. Theriogenology, 63: 1235-1247.

Aw e 1 H., Esh et u L., Ta des s e G., B irhan u A., K h a r S.K. (2009). Estrus synchronization in sheep with synthetic progestagens. Trop. Anim. Health Prod., 41: 1521-1524.

A z a w i O.I., A 1 - M o 1 a M.K. (2010). A study on superovulation using FSH and eCG in Awassi ewes. Trop. Anim. Health Prod., 42: 799-801.

B a r r e t t D.M., B a r 1 le w s k i P.M., B a t i s t a - A r te a g a M., S y m in g to n A., R a w ling s N.C. (2004). Ultrasound and endocrine evaluation of the ovarian response to a single dose of 500 IU of eCG following a 12-day treatment with progestogen-releasing intravaginal sponges in the breeding and nonbreeding seasons in ewes. Theriogenology, 61: 311-327.

B od in L., Drion P.V., R e my B., B ri ce G., Cogni e Y., B e c k e r s J.F. (1997). Anti-PMSG antibody levels in sheep subjected annually to oestrus synchronisation. Reprod. Nutr. Dev., 37: $651-660$.

Boscos C.M., S a martzi F.C., Dellis S., Rogge A., Stefanakis A., Krambovitis E. (2002). Use of progestagen-gonadotropin treatments in estrus synchronization of sheep. Theriogenology, 58: 1261-1272.

C a m b e ro P. (1999). Cuaderno de la explotación de ovino. Serv. Agr. Caja Duero.

Cline M.A., Ralst on J.N., S e a ls R.C., L e w is G.S. (2001). Intervals from norgestomet withdrawal and injection of equine chorionic gonadotropin or PG 600 to estrus and ovulation in ewes. J. Anim. Sci., 79: 589-594.

D a s G.K., N a qvi S.M.K., Guly a n i R., P a ree k S.R., M it t a l J.P. (2000). Effect of two doses of progesterone on estrus response and fertility in acycling crossbred Bharat Merino ewes in a semiarid tropical environment. Small Ruminant Res., 37: 159-163.

D o gan I., Nur Z. (2006). Different estrous induction methods during the non-breeding season in Kivircik ewes. Vet. Med-Czech, 51: 133-138.

E1-S a ied U.M., de la Fuente L.F., Primitivo F.S. (2006). Phenotypic study on total and partial lifetime traits for dairy ewes. J. Dairy Res., 73: 101-108.

Fukui Y., Kohno H., Okabe K., Katsuki S., Yoshizawa M., Togari T., Watanabe H. (2010). Factors affecting the fertility of ewes after intrauterine insemination with frozen-thawed semen during the non-breeding season. J. Reprod. Dev., 56: 460-466.

J u á r e z M., R o m e r o F., A z o r P.J. (2007). Las razas ovinas andaluzas de protección especial: Merina de Grazalema, Churra Lebrijana, Montesina y Merina Negra. In: Las razas ganaderas de Andalucía. II, pp. 301-330.

K a r e t a W., K orm a n K., C e g l a M. (2006). Ovulation level and prolificacy in ewes depending on their age, birth type and percentage of prolific genotype. Reprod. Biol., 2: 73-78.

Knights M., Ramgatti e R., S i ew N., S ingh-Knights D., B ourne G. (2011). Effectiveness of a short-term treatment with progesterone injections on synchrony of lambing and fertility in tropical hair sheep. Anim. Reprod. Sci., 126: 70-75.

Mart e mu c c i G., D' A l e s s a n d ro A.G. (2011). Synchronization of oestrus and ovulation by short time combined FGA, PGF( $2 \alpha)$, GnRH, eCG treatments for natural service or AI fixed-time. Anim. Reprod. Sci., 123: 32-39.

Max we 11 W.M.C. (1986). Artificial insemination of ewes with frozen-thawed semen at a synchronised oestrus. 1. Effect of time of onset of oestrus, ovulation and insemination on fertility. Anim. Reprod. Sci., 10: 301-308.

M c Cappin N., Murray R.D. (2011). Factors affecting the pregnancy rate in ewes following AI. Vet. Rec., 168: 99.

M o e in i M.M., Mog ha d d a m A.A., B a h ir a l e m A., H a j a ri a n H. (2007). Effects of breed and progestin source on estrus synchronization and rates of fertility and fecundity in Iranian Sanjabi and Lori ewes. Pak. J. Biol. Sci., 10: 3801-3807. 
Mos es D., Martínez A.G., I orio G., Valcárcel A., Ham A., P es s i H., Cas tañón R., Maciá A., De Las Heras M.A. (1997). A large-scale program in laparoscopic intrauterine insemination with frozen-thawed semen in Australian Merino sheep in Argentina Patagonia. Theriogenology, 48: 651-657.

Olivera-Muzante J., Fierro S., López V., Gil J. (2011) Comparison of prostaglandin and progesterone-based protocols for timed artificial insemination in sheep. Theriogenology, 75 : $1232-1238$.

Pedrosa S., Arranz J.J., Brito N., Molina A., San Primitivo F., Bayón Y. (2007). Mitochondrial diversity and the origin of Iberian sheep. Gen. Selec. Evol., 39: 91-103.

Quintero-Elisea J.A., Macías-Cruz U., Alvarez-Valenzuela F.D., CorreaCald erón A., González-R e yna A., Lu ce ro-Mag a ña F.A., S ot o-Navarro S.A., Avend a ñ o-R e y e s L. (2011). The effects of time and dose of pregnant mare serum gonadotropin (PMSG) on reproductive efficiency in hair sheep ewes. Trop. Anim. Health Prod., 43: 1567-1573.

Qu irke J.F., Han rahan J.P., Grosling J.P. (1981). Duration of oestrus, ovulation rate, time of ovulation and plasma LH, total oestrogen and progesterone in Galway adult ewes and ewe lamb. J. Reprod Fertil., 61: 265-272.

R a nilla M.J., S u lon J., C a r ro M.D., Man te c ón A.R., B e c k e r s J.F. (1994). Plasmatic profiles of pregnancy-associated glycoprotein and progesterone levels during gestation in Churra and Merino sheep. Theriogenology, 42: 537-545.

R o b i n s o n T.J. (1965). Use of progestagen-impregnated sponges inserted intravaginally or subcutaneously for control of the oestrous cycle in the sheep. Nature, 206: 39-41.

R u s s e 1 A. (1991). Body condition scoring of sheep. In: Sheep and Goat Practice, E. Boden (ed.). Bailliere Tindall: Philadelphia.

S a martzi F., B os cos C., Vain as E., Ts a k a l of P. (1995). Superovulatory response of Chios sheep to PMSG during spring and autumn. Anim. Reprod. Sci., 39: 215-222.

S c a r a m u z zi R.J., C a m p be 11 B.K., D ow ning J.A., K e n d a 11 N.R., K ha lid M., Muñoz -G u t i ér r e z M., S o m c h it A. (2006). A review of the effects of supplementary nutrition in the ewe on the concentrations of reproductive and metabolic hormones and the mechanisms that regulate folliculogenesis and ovulation rate. Reprod. Nut. Dev., 46: 339-354.

S imonetti L., Ramos G., Gardon J.C. (1999). Estrus presentation and distribution in ewes treated with intravaginal sponges impregnated with medroxyprogesterone acetate (MAP) in combination with pregnant mare serum gonadotropin (PMSG). Braz. J. Vet. Res. Anim. Sci., 36: 102-117.

S i mon et t i L., B l a n c o M.R., G a rdon J.C. (2000). Estrus synchronization in ewes treated with sponges impregnated with different doses of medroxyprogesterone acetate. Small Ruminant Res., 38: $243-247$.

S i m on et t i L., R a m o s G., Gar d o n J.C. (2002). Effect of estrus synchronization and artificial insemination on reproductive performance of Merino sheep. Braz. J. Vet. Res. Anim. Sci., 39: 143-146.

Stellflug J.N., Hatfield P.G., Wulster-R a d c liffe M.C., Walker J.W. (2001). Reproductive performance of ewe lambs from ewes from different selection practices with or without induced estrus. Anim. Reprod. Sci., 66: 185-193.

Titi H.H., Kridlim R.T., A ln imerm M.A. (2010). Estrus synchronization in sheep and goats using combinations of GnRH, progestagen and prostaglandin F2alpha. Reprod. Domest. Anim., 45: 594-599.

Ung e r feld R., R u bi a n e s E. (2002). Short term primings with different progestogen intravaginal devices (MAP, FGA, and CIDR) for eCG-estrous induction in anestrus ewes. Small Ruminant Res., 46: 63-66.

Viñoles C., Forsberg M., B anchero G., Rubianes E. (2001). Effect of long-term and short-term progestagen treatment on follicular development and pregnancy rate in cyclic ewes. Theriogenology, 55: 993-1004.

Viñoles C., F or sberg M., Martin G.B., Cajarville C., R e pet to J., M e ikle A. (2005). Short term nutritional supplementation of ewes in low body condition affects follicle development due to an increase in glucose and metabolic hormones. Reproduction, 129: 299-309.

Wil d e u s S. (2000). Current concepts in synchronization of estrus: Sheep and goats. J. Anim. Sci., 77: 1-14. 
Zeleke M., Greyling J.P.C., S chwalbach L.M.J., Muller T., Eras mus J.A. (2005). Effects of progestagen and PMSG on oestrus synchronization and fertility in Dorper ewes during the transition period. Small Ruminant Res., 56: 47-53.

Received: 13 VIII 2014

Accepted: 1 XII 2014 